This item was submitted to Loughborough's Research Repository by the author.

Items in Figshare are protected by copyright, with all rights reserved, unless otherwise indicated.

\title{
A semi-automatic computer-aided assessment approach for marking and providing feedback comments
}

PLEASE CITE THE PUBLISHED VERSION

http://dx.doi.org/10.5220/0005447000930100

PUBLISHER

SCITEPRESS Digital Library

VERSION

AM (Accepted Manuscript)

\section{PUBLISHER STATEMENT}

This work is made available according to the conditions of the Creative Commons Attribution-NonCommercialNoDerivatives 4.0 International (CC BY-NC-ND 4.0) licence. Full details of this licence are available at: https://creativecommons.org/licenses/by-nc-nd/4.0/

\section{LICENCE}

CC BY-NC-ND 4.0

\section{REPOSITORY RECORD}

Adesina, Adewale O., R.G. Stone, Firat Batmaz, and lan Jones. 2019. "A Semi-automatic Computer-aided Assessment Approach for Marking and Providing Feedback Comments". figshare. https://hdl.handle.net/2134/18435. 


\title{
A Semi-Automatic Computer-Aided Assessment Approach for Marking and Providing Feedback Comments
}

\author{
Adewale Adesina ${ }^{1}$, Roger Stone ${ }^{1}$, Firat Batmaz ${ }^{1}$ and Ian Jones ${ }^{2}$

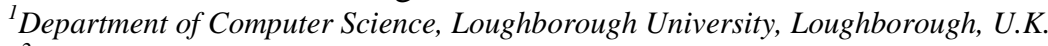 \\ ${ }^{2}$ Mathematics Education Centre, Loughborough University, Loughborough, U.K. \\ \{a.o.adesina, r.g.stone, f.batmaz, i.jones\}@lboro.ac.uk
}

Keywords: Marking \& Feedback Support System, Computer-Aided Assessments, Analytical Assessment Rubrics, Formative Assessment.

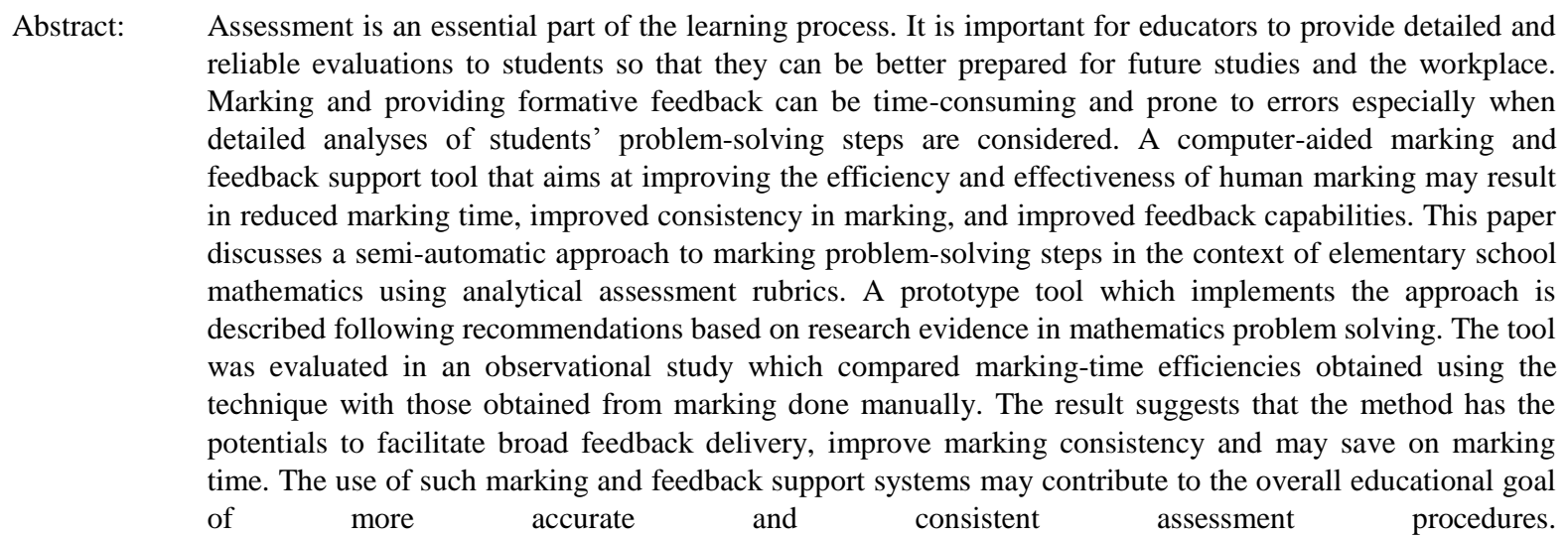

\section{INTRODUCTION}

Assessment is essential in teaching and learning. It can provide information to help educators make better educational decisions. Marking and providing formative feedback on students' performances are essential activities in the educational process (Hattie and Timperley, 2007; JISC, 2010). However the task of providing quality feedback is challenging due to the time and effort it takes to analyse students' performance. Several studies have shown that the most important in-school influence on student learning and achievement is the teacher (Dinham, 2008; Hattie, 2008). Supporting the teacher in classroom and feedback activities is likely to result in better students' performances.

Commonly tests used in classrooms concentrate on the total or representative score for a task (Brown et al., 2008). This information does not usually contribute to quality feedback because it does not help students to answer questions like "What was I good at, and what was I weak at? What do I have to do next (Brown et al., 2008; Mory, 2004)? Marking and giving good feedback requires high quality information. Collecting the data to inform teachers of the process as well as the end product of a problem-solving effort is likely to be valuable in providing this information. A related challenge in assessment practices is inconsistencies in human marked assessments. For instance, Orrell, (2008) showed that human markers are inherently inconsistent and can be influenced by expectations of individual students. Other studies have suggested that inconsistences arise due to high classroom workloads for teachers and the drudgery of marking. Having teacher to assess detailed problem-solving steps is likely to lead to even greater workloads.

Computer-Aided Assessment (CAA) is increasingly being used to address these challenges. The benefits of CAA have been widely reported. These include, increased variety of assessed tasks, the provision of instantaneous feedback, as well as increased objectivity and resource saving (Bull and McKenna, 2004; Conole and Warburton, 2005; 
Hollingsworth, 1960). However the focus of many CAA systems tends to be on providing fully automatic assessment of student work. Fewer studies have examined the combination of human and computer in marking and provision of feedback comments. Semi-automatic assessment is a term that has been used to describe the cooperation between human markers and the computer in assessment (Herding and Schroeder, 2011; Bescherer et al., 2011; Sargent, J et al., 2004).

This study describes a semi-automatic assessment method for marking students' work and providing feedback comments in the context of elementary school mathematics. The study further evaluates the effectiveness of the approach in reducing the time spent in marking. The core research questions that guided the study can be stated as follows:

- How can semi-automatic CAA systems be designed to assess problem-solving steps with the aim or providing rich data for scoring and feedback comments?

- Does using this technique lead to reduced marking time?

The significance of the research is two-fold. First, results of this study may enable the assessment of problem-solving processes for the purpose of providing broad feedback. This may aid both instructors and researchers to better understand students' problem-solving steps and behaviour in detail. Second, it may contribute to providing empirical evidence on how the semi-automatic approach may possibly reduce marking workloads. This could be especially useful in situations where there are large student populations.

The rest of this paper is structured as follows: First a background to this work and the computeraided assessment is first outlined. This is followed by a description of the semi-automatic assessment approach adopted in the present study. After this, the implementation of the approach on a prototype tool is described in detail. Empirical evaluations of the prototype tool with discussions are then presented.

\section{EDUCATIONAL ASSESSMENT}

\subsection{Assessments and Feedback}

Assessment has been defined as the practice of systematically, gathering, analysing, and interpreting evidence to determine how well students' learning matches the expectations and using the resulting information to understand and improve student learning (Suskie 2010). An essential purpose of assessment is to improve learning. The empirical research reviewed by Black and William (1998) provides evidence that classroom assessment raises students' achievement when information gathered about the processes and products of learning are used to adapt teaching and formative feedback is given to students to improve their learning. Also, Hattie and Timperley (2008) showed that feedback from teachers to students is important and has the largest effect size in students achievement (Hattie 2009). An implication of this is that improving the effectiveness of teachers will improve education significantly.

\subsection{Problem Solving in Elementary Mathematics - an Illustration}

Learning in mathematics involves students solving problems in systematic ways (National Council of Teachers in Mathematics (NCTM) 2000). When problem solving is used, the emphasis is usually on finding relevant and engaging tasks or problems that help illustrate or assess a mathematical concept or procedure. Many scholars hold the view that effective assessment of problem solving should look at more than the answers students give. For instance, Szetela, (1992) argued that teachers should analyse student processes and as much as possible help them to communicate their thinking. This is commonly because students make mental calculations without explanations and only provide ending answers. This often does not reveal sufficiently the student's work and thinking.

The Oregon mathematics scoring model (Arter 1993), NWREL Mathematics ProblemSolving Model ${ }^{\mathrm{TM}}$ and the California Assessment Program (Pandey 1990) draws our attention to at least four distinctive categories that may be scored in problem-solving performance assessment. These include conceptual understanding, procedural understanding, problem-solving strategies and communication. Conceptual understanding is generally understood to describe the ability to interpret the problem and select appropriate information to apply a strategy for a solution. Procedural knowledge refers to weather students choose mathematical facts and operations to help them solve a problem and how well they apply those facts and operations (Rittle-Johnson and Alibali 1999). Problem-solving strategies has been described as the combination or sequence of skills used in working toward the solution, which is 
demonstrated by good reasoning leading to a successful resolution of a problem (Arter 1993).

As an example, we consider the following elementary mathematics problem.

Jason owned a factory that employs 53 workers. He hired another 16 workers. He then hired another 7 workers. How many workers are there at the factory altogether? (Carpenter and Moser 1984)

The problem might typically be solved in two steps; each step comprising pairing two numbers and adding them. The way in which the numbers in the problem are paired may reflect the strategy adopted by the problem solver. For instance, the number may paired in the order they appear in the question $((53+16)+7)$ or the numbers may be paired using the understating of numbers that bonds to multiples of 10 i.e. $((53+7)+16)$. This later approach suggests a better conceptual understanding of addition, and reduces the need to undertake burdensome computation to obtain the result (Gray and Tall, 1994).

Instead of scoring solutions only, assessors may analyse the responses to the problems of the basis of the different categories. One focus might be on strategies used, another may be on answers or procedures used. Feedback may be provided on each of these categories separately or together. However, such detailed assessment will add to the burden of marking and feedback.

\section{THE SEMI-AUTOMATIC ASSESSMENT APPROACH}

\subsection{General Concept}

Semi-automatic marking aims to reduce the effort an assessor needs to put in to mark and provide feedback comments on students' work. Usually in fully automatic assessment systems, the assessor develops fair and consistent rules to handle different answers and the exceptions (Bull and McKenna, 2004). These are usually prepared in advance to the students answering the questions. The approach adopted in this study does not attempt to consider all possibilities of students' responses, as these sometimes may be unlimited. Instead of grading submitted works in a black box, it relies on the assessor to make judgments, assign scores and provide feedback comments. These are then reused in submissions with similar properties.

The approach considered in this work is a combination of three techniques; the capture of problem-solving steps from interaction traces, assessment with analytic rubrics and re-use of assessed items using the case-based reasoning methodology (Aamodt and Plaza, (1994) . This is illustrated in Figure 1.

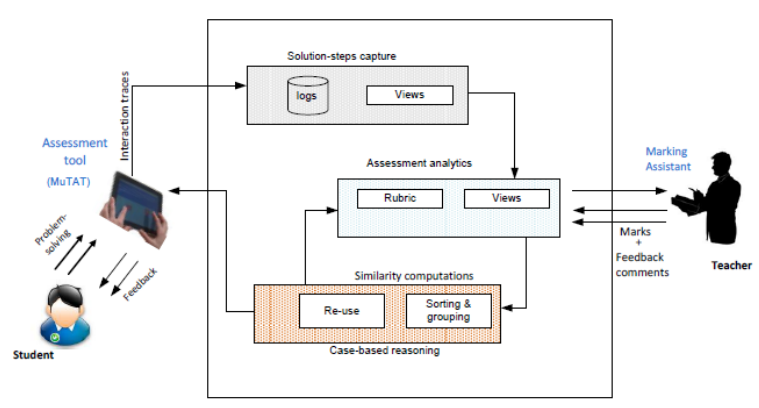

Figure 1:Semi-automatic assessment architecture.

The figure shows that the problem-solving steps are captured from interactions on an assessment tool. The steps are presented to the teacher who uses an analytic rubric scheme to mark and make feedback comments. The teacher's effort is reused as efficiently as possible. The results are then provided to the student. The details of the techniques are provided in the following sections.

\subsection{The Capture of Problem-Solving Steps}

As mentioned in Section 2.2, detailed assessment requires the consideration of steps used to solve problems. This requires the use of an assessment environment that captures and logs the actions of a solution effort. A Multi-Arithmetic Tool (MuTAT) allows this to be done. The tool, shown in Figure 2 and 3 provides an environment for rich interactions between a problem text and solution items. It explicitly allows the matching of key information in the problem statement with the related component a students' response.

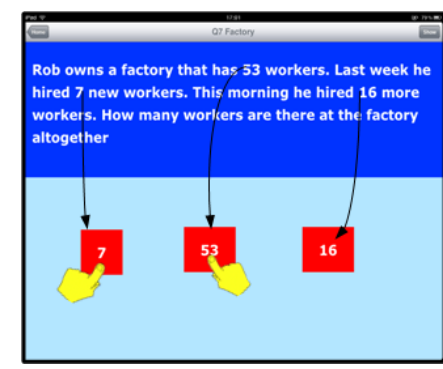

Figure 2: The Multi-Touch Arithmetic Tool (MuTAT). 
The MuTAT provides several benefits; it compels the student to break their problem-solving into small steps while entering their solutions. This way the thinking process is revealed as problems are being solved; here the reasoning behind a wrong (or right) answer is not lost. Additionally, the software provides visual representation of key elements in the problem-solving process which may be used by teachers and students themselves to understand how the problem was approached. Because MuTAT combines visual representations, with interactive actions within a solution workspace, problemsolving using different strategies are accommodated. Details of the capture technique have been described in a recent study (Adesina et al., 2014).

\subsection{Assessment Analytics with Rubrics}

For any type of assessment used to assign student grades, it is recommended that scoring rubrics be used (Garfield, 1994). Rubrics have been described as a "scoring tool that lays out the specific expectations for an assignment" (Stevens and Levi, 2011 , p. 4), they are usually aligned along clearly defined learning intentions or curriculum objectives, and they simplify the grading process. Charles et al., (1987) referred to rubrics as a statement of characteristics associated with different levels or grades of performances by which a student work can be understood. Rubrics can be applied in assessments evaluating detailed solution steps. Two types of rubrics which are commonly used are holistic and analytic. While holistic rubrics provide a single base or an overall impression of a student's performance on a task, analytic rubrics provide specific feedback along several dimensions (Jonsson and Svingby, 2007; Stevens and Levi, 2011).

The semi-automatic assessment will require analytic rubrics to properly assess and provide feedback comments on different categories of a problem-solving effort. For example in the arithmetic problem in Section 2.4, an assessor may be able to separate what the student is trying to do based on his understanding from his ability to perform calculations. This way, the student can get feedback on three categories i.e. calculation, conceptual understanding, and strategy used. This is in contrast to the assignment of single score as in holistic rubrics. This technique provides the opportunity for broad feedback. Other assessment information such as time taken to complete a step, overall time, and count of interactions can also be obtained. Garfield, (1994) suggests that these types of attributes need not be given a score or grade, but they can inform the teacher about understanding, feelings, and frustrations and can serve as inputs to modifying instruction.

Table 1: Analytical rubric for mathematics problem solving

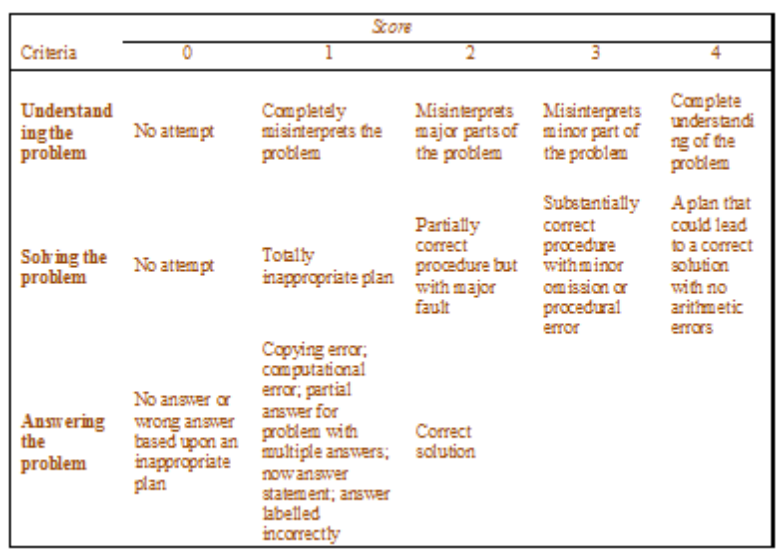

(Adapted from Charles et al., 1987 and Szetela, 1992)

Using a scoring rubric such as outlined in Table 1 to assign points (such as $0,1,2 \ldots$ ) and provide feedback comments to different components of the assessment provides opportunities for richer assessments and feedback.

\subsection{Re-use of Assessed Items - Marks and Feedback Comments}

The semi-automatic method proposed in this work aims to reuse the teachers' feedback and marking experiences. As discussed in Section 2.2, semiautomatic assessment seeks to take advantage of the strengths of human marking and computer-based marking. This may be achieved by having the decisions made by human-markers re-used in as many scenarios as possible. The Case Based Reasoning (CBR) methodology ones (Richter and Rosina, O, 2013) provides a "reuse" stage where matching cases are selected and reused. CBR involves matching similar problems and their solutions to new ones. Unlike in knowledge based systems that relies on the use of rules to guide decision process. CBR looks for similarities between the current needs and previous examples of similar problems and the attendant solutions. Reusing information and knowledge in retrieved cases reduces repetition which can be inefficient and sometimes results in inconsistencies. Figure 3 shows a scenario where a solution to the example problem in Section 2.2 is marked and comments provided by an assessor. 


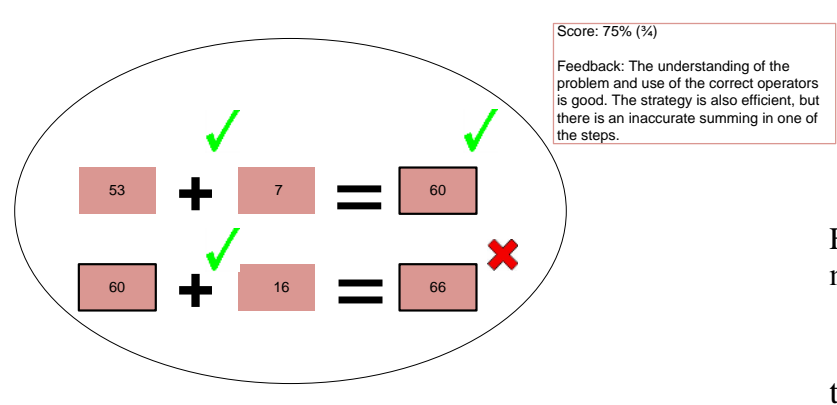

Figure 3: Detailed marking and feedback comments.

In the figure, points are allotted to the assessable pieces based on a pre-determined rubric. The assigned marks and feedback for solution attributes is reusable on different granular levels. The reuse of assessed items enhances objectivity and consistency. Also, it makes it possible such that when moderation is carried out the results are applied consistently across all student submissions and is likely to bring out savings of time and resources. In this paper, the method of grouping by exact matches was adopted for similar solutions

\section{IMPLEMENTATION ON MARKING TOOL}

The techniques outlined in the previous section have been implemented in a prototype tool. This section describes and discusses the implementation of the assessment method on a prototype tool called Marking Assistant (shown in Figure 1). The tool was designed to ease the marking of the component parts of students' submitted work. The Marking Assistant has five main functional requirements; first it should be able to easily apply an analytic rubric scheme, it should be able to re-use scores for similar solutions, it should allow input of marks according to grouped criteria, it should allow of entry of feedback comments. Lastly, it should facilitate the generation of feedback summaries and reports. The user interface of the editor is shown in Figure 4.

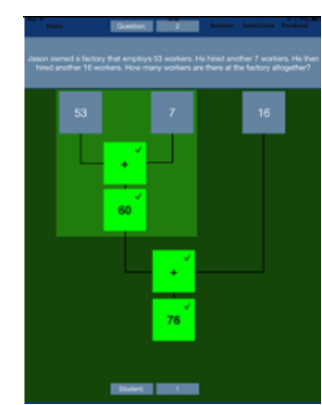

Figure 4: The Marking Assistant user interface showing marks assigned to "score-able" pieces.

The assessor simply taps on the score-able pieces to assign scores and feedback comments. The computer takes the marks and comments and applies these to similar submissions on the same question. As can be seen in the figure, when a score-able component is assessed, other solutions with the same properties are automatically assigned the same score when they are encountered. During this process, the examiner may enter feedback comments for the actions and entered solution. Because similar solutions have been grouped together for assessed attributes, the same feedback is applied consistently to all.

\section{EVALUATION STUDY}

The feedback support tool was evaluated regarding the usability and time-saving potentials. The main objective of the evaluation was to compare markingtime on the application with that on paper. Undergraduate students $(\mathrm{N}=8)$ in a university in England were the participants in the study. The evaluation was performed on a voluntary basis and the student used the tool and paper independently after being guided on general requirements. The details of the study and results of the observational study are described in this section.

\subsection{Study Design}

\subsubsection{Participants}

Eight participants were used in the study. They were all required to mark the responses of 20 students on paper and the marking assistant tool. The students' solutions explicitly showed all the steps to the answer.

\subsubsection{Questions}

The study used four arithmetic word problems which commonly, solving the problem requires two steps using two arithmetic operators. Participants were required to mark four questions two on each media. The first question to be marked 
on both media (tool and paper) requires the use of addition operators in both steps. The second question will require using both addition and subtraction operators. The lists of both question types are shown in Table 2.

Table 2: Test questions.

\begin{tabular}{|c|c|c|c|c|}
\hline \multicolumn{2}{|c|}{$\begin{array}{l}\text { Question with addition } \\
\text { only }\end{array}$} & \multicolumn{3}{|c|}{$\begin{array}{c}\text { Question requiring } \\
\text { both addition \& subtraction }\end{array}$} \\
\hline \multicolumn{2}{|c|}{ Question } & \multicolumn{3}{|c|}{ Question 2: Sam has } \\
\hline \multicolumn{2}{|c|}{$\begin{array}{l}\text { owned a factory that } \\
\text { employs } 53 \text { workers. He } \\
\text { hired another } 7 \text { workers. He } \\
\text { then hired another } 16 \\
\text { workers. How many } \\
\text { workers are there at the }_{\text {factory altogether? }}{ }^{\text {a }}\end{array}$} & \multicolumn{3}{|c|}{$\begin{array}{l}21 \text { books, he got } 9 \text { more } \\
\text { and gave } 13 \text { to Owen. At } \\
\text { the end, how many books } \\
\text { did Sam have? }\end{array}$} \\
\hline \multicolumn{2}{|c|}{$\begin{array}{l}\text { Question 3: Sara has } 8 \\
\text { sugar donuts. She also has } \\
15 \text { plain donuts and } 32 \text { jam } \\
\text { donuts. How many donuts } \\
\text { does Sara have altogether? } \\
\text { b }\end{array}$} & \multicolumn{3}{|c|}{$\begin{array}{l}\text { Question 4: There are } \\
24 \text { books on a shelf, } 11 \\
\text { more where added and then } \\
6 \text { taken away. At the end, } \\
\text { how many books were } \\
\text { there? }\end{array}$} \\
\hline \multicolumn{5}{|c|}{$\begin{array}{l}\text { Adapted from (Carpenter and Moser 1984) }{ }^{\mathrm{a}} \text { and } \\
\text { (Gilmore and Bryant 2006) }^{\mathrm{b}}\end{array}$} \\
\hline \multicolumn{5}{|c|}{$\begin{array}{l}\text { A comparative cross-over experimental design } \\
\text { was used. To minimize ordering effects different } \\
\text { combinations of question type and marking media } \\
\text { were created as shown in Table } 3 \text {. The participants } \\
\text { were randomly assigned into the four different } \\
\text { combination categories. }\end{array}$} \\
\hline \multicolumn{5}{|c|}{$\begin{array}{l}\text { Table 3: Order in which participants marked on paper and } \\
\text { the Marking Assistant. }\end{array}$} \\
\hline No. & \multicolumn{2}{|c|}{ Marking order } & $\begin{array}{r}\text { Tablet } \\
\text { Question }\end{array}$ & $\begin{array}{r}\text { Paper } \\
\text { Question }\end{array}$ \\
\hline 1 & Tablet, Paper, Pape & ,Tablet & 1,2 & 3,4 \\
\hline 2 & Tablet, Paper, Pape & , Tablet & 3,4 & 1,2 \\
\hline 3 & Paper, Tablet, Tabl & t, Paper & 1,2 & 3,4 \\
\hline 4 & Paper, Tablet, Tabl & & 3,4 & 1,2 \\
\hline
\end{tabular}

Each of the participants marked the four questions as answered by 20 students. Two questions were marked on each media.

\subsubsection{Measures}

The main measurement made was the time it took the participants to complete the marking of the questions on the two media used. On the Marking Assistant the proportions of items marked manually and automatically were recorded.

\subsection{Results}

Scoring on paper and the Marking Assistant tool were successfully completed by all the participants. The times it took the participants to complete the marking on both media are shown in Figure 5.

Scoring on paper and the Marking Assistant tool were successfully completed by all the participants. The times it took the participants to complete the marking of all the questions on both media are shown in Figure 5.

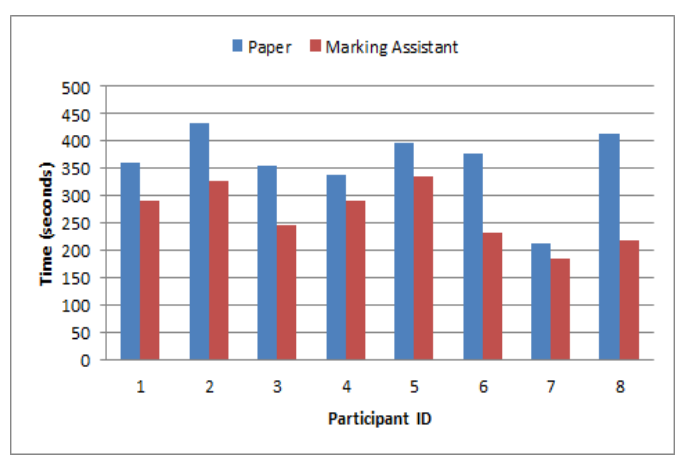

Figure 5: Marking time on paper and the Marking Assistant

As can be seen from the figure, all the participants spent less time on the tool compared to paper. The mean time spent on the questions on the Marking Assistant was 265.5 seconds while 360.9 seconds was spent marking on paper. This difference was significant $\mathrm{t}(7)=4.84, \mathrm{p}=0.00188$.

The Marking Assistant therefore saved on marking time. The relative proportion of items manually marked and those marked automatically by the computer re-using the manually marked results is shown in Figure 6. 


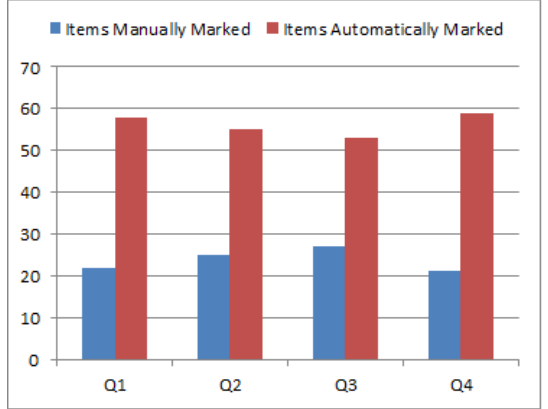

Figure 6: Proportion of marking done manually and automatically.

From the figure above it can be seen that in all the questions more items were marked automatically (70\%) than manually (30\%). This is because the computer handled all the repetitive marking which evidently enabled time to be saved on the Marking Assistant tool.

\section{DISCUSSION}

This study suggests a semi-automatic assessment approach for CAA using the case-based reasoning methodology. It explored how marking efficiency and consistency may be improved while considering detailed problem-solving steps.

The first question in this study sought to determine was how a semi-automatic assessment CAA may be designed to help assess and score more than final answers of a problem-solving effort. The approach adopted combined three techniques; capture of problem-solving steps, application of analytical rubric and case-based reasoning. The implementation of the assessment rubric and casebased-reasoning techniques were successfully carried out on the Marking Assistant tool described in Section 4. A two-step elementary mathematics problem was broken down into four assessable components to increase the depth of what is assessed. Because the tool automatically re-uses judgment features of the marker, consistency in application of the judgements to problems with similar properties is ensured.

As regards the potential efficiency of the system, the observational study provided useful insights. The results show that the Marking Assistant enabled significant time savings compared to marking done entirely manually. For the four-components marking examined, up to $70 \%$ of the required assessment was done automatically. This suggests that the efficiency of an assessor may be improved by using as cases manually-assessed components. However, the observational study has some limitations. Although classroom test questions and solutions were used, undergraduate students were the participants in the marking exercises, rather than actual primary school teachers. Since the study objective was to obtain marking time from two mediums by the same individual, results from students with fewer marking experiences than actual classroom teachers helps demonstrate the potentials of the approach.

The findings suggest several implications. The improved efficiency in marking and feedback is important to assessors such as teachers, because they can reduce their marking workloads and devote effort to other teaching activities. The improved accuracy and consistency in marking ensures that correct and fair marks are giving to all students possibly resulting in more satisfied teaching staff, students, and administrators. The system may assist students in monitoring and reflecting on their problem-solving processes and also to understand how they were graded on a piece of work. The clear rubrics may also be used to communicate to parents the strengths and successes that students have demonstrated.

All assessment procedures have strengths and limitations. It is important to note that much work has to be done before hand in design of questions and software. Some authors have cautioned that the less writing a student does in an assessment task, the more work the assessor has do in creating the task (Brown et al., 2008; Bull and Mckenna, 2004). Sangwin (2013), also pointed out that a potential limitation in emerging semi-automatic CAA systems as the loss of immediate feedback. This is because marking that requires the attention of a human assessor comes with an inevitable delay. Instant feedback is a big advantage of fully automatic systems. However, the gains of detailed and personalized feedback and the potential markingtime savings gained from the re-use of assessed items may allow assessors to respond quicker than with manual scoring and feedback methods.

\section{CONCLUSIONS}

This study investigated a semi-automatic approach to assessment and feedback. In the semi-automatic approach used, the attributes of a student's response with the judgement (scores and feedback comments) made by an assessor are carefully recorded and linked together. The computer is then used to sort, classify and re-apply these judgements and feedback comments to similar students' responses. The findings suggest that in general, that process evaluation using analytic rubrics and case-based 
reasoning may enhance detailed marking and feedback. The use of the case-based reasoning methodology helps improve the consistency and reliability in assessment and can potentially save in marking time.

The semi-automatic approach was used in the well-researched domain on elementary mathematics allowing for prediction of distinct strategies to obtain answers. The approach may be used beyond basic arithmetic.

\subsection{Further Work}

The present study only considered exact matches of the students work on which an assessor's marking and feedback experiences are reused as is. It may be possible to increase the scope of similarity assessments and adapt previous experiences to new problems situations encountered. Further investigations on this may be fruitful.

\section{REFERENCES}

Aamodt, A., \& Plaza, E. (1994). Case-Based Reasoning: Foundational Issues, Methodological Variations, and System Approaches. AI Communications, 7(1), 39-59.

Adesina, A., Stone, R., Batmaz, F., \& Jones, I. (2014). Touch Arithmetic: A process-based Computer-Aided Assessment approach for capture of problem solving steps in the context of elementary mathematics. Computers \& Education, 78, 333-343.

Bennett, R. E., Braswell, J., Oranje, A., Sandene, B., Kaplan, B., \& Yan, F. (2008). Does it Matter if I Take My Mathematics Test on Computer? A Second Empirical Study of Mode Effects in NAEP. The Journal of Technology, Learning and Assessment, 6(9).

Bescherer, Christine, Herding, Daniel, Kortenkamp, Ulrich, Muller, Wolfgang, \& Zimmermann, Marc. (2011). E-Learning Tools with Intelligent Assessment and Feedback for Mathematics Study. Idea Group Inc (IGI).

Black, P., \& Wiliam, D. (1998). Assessment and Classroom Learning. Assessment in Education: Principles, Policy \& Practice, 5(1), 7-74.

Brown, G., Irving, E., \& Keegan, P. (2008). An Introduction to Educational Assessment, Measurement and Evaluation. Pearson Education New Zealand Limited.

Bull, J., \& McKenna, C. (2004). Blueprint for computerassisted assessment. London: RoutledgeFalmer.

Carpenter, T. P., \& Moser, J. M. (1984). The Acquisition of Addition and Subtraction Concepts in Grades One through Three. Journal for Research in Mathematics Education, 15(3), 179-202.

Charles, R., Lester, Frank, \& O'Daffer, Phares. (1987). How To Evaluate Progress in Problem Solving.
National Council of Teachers of Mathematics, 1906 Association Drive, Reston, VA 22901.

Conole, G., \& Warburton, B. (2005). A review of computer- assisted assessment. ALT-J, 13(1), 17-31.

Dinham, S., 2008. How to Get Your School Moving and Improving: An Evidence-based Approach. Aust Council for Ed Research.

Garfield, J. . B. (1994). Beyond testing and grading: Using assessment to improve student learning. Journal of Statistics Education, 2(1), 1-11.

Gray, E.M., Tall, D.O., 1994. Duality, Ambiguity, and Flexibility: A "Proceptual" View of Simple Arithmetic. J. Res. Math. Educ. 25, 116-140.

Hattie, J. (2008). Visible Learning: A Synthesis of Over 800 Meta-Analyses Relating to Achievement. Routledge.

Hattie, J., \& Timperley, H. (2007). The Power of Feedback. Review of Educational Research, 77(1), 81-112.

Herding, D., \& Schroeder, U. (2011). Using Capture \& Replay for Semi-automatic Assessment. In CAA 2011 International Conference.

Hollingsworth, J. (1960). Automatic graders for programming classes. Commun. ACM, 3(10), 528529.

JISC. (2010). Effective Assessment in a Digital Age: A guide to technology-enhanced assessment and feedback. Retrieved 2 February 2014, from http://www.jisc.ac.uk/media/documents/programmes/e learning/digiassass_eada.pdf.

Jonsson, A., \& Svingby, G. (2007). The use of scoring rubrics: Reliability, validity and educational consequences. Educational Research Review, 2(2), 130-144.

Jordan, S. (2013). E-assessment: Past, present and future. New Directions, 9(1), 87-106.

Mory, E. H. (2004). Feedback Research Revisited. In Handbook of Research on Educational Communications and Technology (2nd ed.) (pp. 745783). Mahwah, NJ, US: Lawrence Erlbaum Associates Publishers.

National Council of Teachers in Mathematics (NCTM). (2000). Principles and Standards for School Mathematics. Reston, VA: NCTM.

Orrell, J. (2008). Assessment beyond belief: the cognitive process of grading. Balancing Dilemmas in Assessment and Learning in Contemporary Education, 251-263.

Richter, M. M., \& Rosina, O. (2013). Case-based reasoning: a textbook. London: Springer.

Rittle-Johnson, B., \& Alibali, M. W. (1999). Conceptual and procedural knowledge of mathematics: Does one lead to the other? Journal of Educational Psychology, 91(1), 175-189.

Sangwin, C. (2013). Computer Aided Assessment of Mathematics. Oxford University Press.

Sargent, J, Wood, M.M, \& Aderson, S.M. (2004). A human-computer collaborative approach to the marking of free text answers. In 8th International 
Computer Assisted Assessment Conference,. Loughborough University.

Stevens, D. D., \& Levi, A. J. (2011). Introduction to Rubrics: An Assessment Tool to Save Grading Time, Convey Effective Feedback, and Promote Student Learning. Stylus Publishing, LLC.

Suskie, L. (2010). Assessing Student Learning: A Common Sense Guide. John Wiley \& Sons.

Szetela, W. (1992). Evaluating Problem Solving in Mathematics. Educational Leadership, 49(8), 42-45. 